\title{
SCALES IN THE MEANING OF ADJECTIVES
}

\author{
SVETA KRASIKOVA \\ University of Tübingen
}

\section{A B S T R AC T}

The goal of this paper is to show that a degree-based semantics for comparative constructions in English, based on a degree ontology going back to Cresswell (1976), meets the challenge of polarity effects in antonymous adjectives, once it is properly adapted to deal with measure expressions and the so called norm-related inferences. I present an alternative to theories that rely on a shift from degrees as points to degrees as intervals as proposed in von Stechow (1984a). My approach builds on the assumption that degrees constitute simple ordinal scales and measures are introduced at the LF by the necessity of interpreting numerals. The proposal is evaluated against the data from two languages with completely different polarity patterns, English and Russian.

\section{[1] INTRODUCTION}

Any theory of comparatives employs some notion of a degree. Following the work of Cresswell (1976), most contemporary theories of comparison handle degrees as abstract entities forming part of the object language. ${ }^{1}$ Klein (1991) calls such theories degree-based. The main tenet of a degree-based analysis is the presence of an object of degree type in its underlying semantic ontology. The classical method to construct degrees inspired by the Frege-Russell treatment of cardinal numbers was first elaborated in Cresswell (1976). Cresswell defines degrees as equivalence classes of individuals indistinguishable relative to a relevant gradable property. For example, John's tallness is conceptualized as a set of entities that are considered exactly as tall as John and the degree of John's intelligence is a set of entities that are indistinguishable from John relative to how intelligent they are. Under this view, one would take John's shortness to be the same object as John's tallness, i. e. degrees associated with antonymous predicates would be expected to be identical. Not only is this assumption ontologically plausible, it is also crucial for deriving the equivalence in (1), which Kennedy (1997) calls a minimal requirement of any theory of comparatives.

(1) Judy is taller than Sam. $\Leftrightarrow$ Sam is shorter than Judy.

[1] A different tradition going back to Lewis (1970) is to treat degrees as contextual coordinates, for a comparison see Klein (1980); Kennedy (2007); Sassoon (2007); van Rooij (2008). 
However, as pointed out in Rullmann (1995), identifying polar degrees appears problematic for the treatment of some degree constructions. For example, it makes it difficult to explain the deviancy of the sentences with negatively polar adjectives in (2) and (3) below. If 'tall' and 'short' relate Judy to the same degree why should this polar asymmetry arise? Rullmann remarks that both (2-b) and (3-b) presuppose that Judy is short, whereas (2-a) and (3-a) are neutral in this respect.

(2) a. Judy is $1.80 \mathrm{~m}$ tall.

b. ??Judy is $1.80 \mathrm{~m}$ short.

(3) a. How tall is Judy?

b. ?How short is Judy?

Along with measure phrase constructions and degree questions, equatives with ratio modifiers also display polar asymmetry, see (4).

(4) a. Judy is twice as tall as Sam.

b. ??Judy is twice as short as Sam.

Another environment that discloses markedness of negative poles are subdeletion comparatives with differential measure phrases. It appears that a differential is only licensed in a subdeletion comparative if the embedded predicate is positively polar as illustrated by the contrast in (5).

(5) a. The doorway is $5 \mathrm{~cm}$ higher than the shelf is wide.

b. The doorway is $5 \mathrm{~cm}$ lower than the shelf is wide.

c. *The doorway is $5 \mathrm{~cm}$ higher than the shelf is narrow.

d. *The doorway is $5 \mathrm{~cm}$ lower than the shelf is narrow.

The paradigm in (5) is discussed in Bierwisch (1989) who observes that the variants of (5-c) and (5-d) without differentials can only receive a so called N-reference reading. $\mathrm{N}$-reference is a comparison with a norm salient in the context. For instance, (6) can only be understood to convey that the extent to which the shelf is narrow is surpassed by the extent to which the doorway is high; it could be truthfully uttered in a situation in which the doorway is very high and the shelf is not very narrow. Bierwisch calls the interpretation of (6) norm-related. Note that Rullmann's characterisation of the deviant examples (2-b) and (3-b) is captured by norm-relatedness as well. Markedness of negative polar adjectives reflected in the licensing of numerical modifiers is evidently related to the phenomenon of norm-relatedness.

(6) The doorway is higher than the shelf is narrow. 
We would expect a language in which norm-related readings are distributed differently from English to have a different polarity pattern. This expectation is borne out for Russian. On the one hand, Russian is known to have a more restricted distribution of numerals with gradable adjectives: they are licensed with the comparative form of an adjective only, cf. (7)-(8). On the other hand, except for comparatives of inequality, Russian degree constructions are norm-related regardless of the polarity of the predicate. For example, in contrast to English, Russian equatives can only receive an N-reference interpretation. In (9) both Katja and Larissa are understood to be tall or short, respectively.

(7) Кровать на 4 см/ в 2 раза шире, чем диван

bed by $4 \mathrm{~cm} /$ twice wider than sofa

'The bed is $4 \mathrm{~cm}$ wider than the sofa./The bed is twice as wide as the sofa.'

(8) Кровать $80 \mathrm{~cm}$ *широкая/*узкая/ шириной

bed $\quad 80 \mathrm{~cm}$ wide/ narrow/ width-INSTR

'The bed is $80 \mathrm{~cm}$ wide.'

(9) Катя такая же высокая/ низкая, как и Лариса

Katja that EMPH tall/ short as also Larissa

'Katja and Larissa are equally tall/short.'

This paper strives to account for polarity effects in English without changing the standard ontological assumptions about the nature of degrees. I tackle this task by spelling out the correlation between the observed polar asymmetries and normrelatedness. Furthermore, I investigate the contrast between English and Russian to embed my conclusions in a broader cross-linguistic picture.

The paper is structured as follows. Section [2] gives a background on a degreebased analysis of comparatives; in section [3] I discuss how polarity effects are accounted for by different theories of antonyms; in section [4] I first propose a new analysis and apply it to the English data, the last part of that section is concerned with antonyms in Russian; section [5] is a conclusion.

\section{[2] DEGREE-BASED APPROACH}

In this section I introduce underlying ideas of a degree-based approach to the analysis of constructions with gradable adjectives. The crucial notion is that of a degree. As an example, let me demonstrate a standard way of constructing a degree of tallness. I rely on a recent exposition in von Stechow (2008). We start with the relation 'taller than' holding of individuals of type $e$, which is empirically given and has the property of being irreflexive, asymmetric and transitive. By assumption, each gradable predicate is associated with at least one such relation. Let us denote this relation as $\succ_{\text {tall }}$ and its field as $\mathrm{F}\left(\succ_{\text {tall }}\right)$. Using this relation, we may define the equivalence relation 'exactly as tall as' with the same field. 
(10)

$$
\begin{aligned}
& \forall x, y \in F\left(\succ_{\text {tall }}\right): y \approx_{\text {tall }} x \text { iff } \forall z \in F\left(\succ_{\text {tall }}\right): \\
& {\left[y \succ_{\text {tall }} z \text { iff } x \succ_{\text {tall }} z\right] \wedge\left[z \succ_{\text {tall }} y \text { iff } z \succ_{\text {tall }} x\right]}
\end{aligned}
$$

The tallness degree of individual $u$, notated as $[u]_{\text {tall }}$, can now be defined as a subset of $\mathrm{F}\left(\succ_{\text {tall }}\right)$ corresponding to the equivalence class of $u$ relative to $\approx_{\text {tall }}$, see (11-a). Tallness degrees are thus predicates of individuals, i e. they have the semantic type et, and denote sets of individuals which are indistinguishable with respect to how tall they are, see (11-b).

$$
\begin{array}{ll}
\text { a. } & \forall u \in F\left(\succ_{\text {tall }}\right):[u]_{\text {tall }}=\left\{x: x \approx_{\text {tall }} u\right\} \\
\text { b. } & D_{\text {tall }}=\left\{[u]_{\text {tall }}: u \in F\left(\succ_{\text {tall }}\right)\right\}
\end{array}
$$

It is common practice to introduce type $d$ representing objects of this kind into the semantic ontology.
a. Let $d$ be a semantic type of degrees.
b. Let $D_{d}$ consist of disjoint sets of degrees of various sorts.

Constructed as equivalence classes, tallness degrees can be related to each other by a second order relation based on $\succ_{\text {tall }}$, as defined below:

$$
\forall d, d^{\prime} \in D_{\text {tall }}: d>_{\text {tall }} d^{\prime} \text { iff } \forall x \in d, \forall y \in d^{\prime}: x \succ_{\text {tall }} y
$$

Like their domains, degrees constitute a scale structure. I shall call a scale a tuple consisting of a set of degrees of a particular sort and an ordering '>' on this set.

Call each pair $\left\langle D_{a},>_{a}\right\rangle$, such that $D_{a} \subseteq D_{d}$ and $>_{a}$ is the ordering on $D_{a}$, a scale of degrees in $D_{a}$.

Degree scales like $\left.\left\langle D_{\text {tall }},\right\rangle_{\text {tall }}\right\rangle$ constitute an ordinal system of measurement, which implies that degrees of tallness can be compared by the 'greater than' or 'less than' relation, but the operations of addition or subtraction cannot be meaningfully applied to them. Thus, degrees as equivalence classes represent only the order of the entities they correspond to, they do not encode the distance between them.

Cresswell (1976) suggests that degrees are introduced into a semantic representation by lexical entries of gradable predicates, which take degrees as their arguments. More specifically, he proposes to analyse gradable adjectives as expressing relations between individuals and degrees of the relevant sort. For example, the adjective 'tall' is treated as a function that maps a degree of tallness to a set of individuals whose height is represented by that degree. The assignment of an individual to its unique degree of some sort is called a measure function. A gradable adjective is therefore associated with a certain kind of measure function. The measure function that relates an entity to its height in world $w$ is defined in (15-a). Given this measure function, we may formulate the lexical entry for 'tall' 
as in (15-b).

$$
\begin{aligned}
& \text { a. } \operatorname{HEIGHT}_{w}:=\lambda x \iota d\left(d \in D_{\text {tall }} \wedge x \in d\right) \\
& \text { b. } \llbracket \text { tall } \rrbracket=\lambda w \lambda d \in F(>\text { tall }) \lambda x \operatorname{HEIGHT}_{w}(x)=d
\end{aligned}
$$

An analysis of a simple comparative in (16) should intuitively involve a comparison of the degree representing Judy's height to the degree representing Sam's height by means of a relation $\succ_{\text {tall }}$. There is a variety of theories trying to capture this intuition, for a comparison see von Stechow (1984a). The simplest view goes back to Russell's (1905) definite-style analysis. According to it, sentence (16-a) has the truth conditions in (16-b).

$$
\begin{aligned}
& \text { a. Judy is taller than Sam is. } \\
& \text { b. } \quad \iota d\left(\operatorname{HeIGHT}_{w}(J)=d\right)>_{\text {tall }} \iota d^{\prime}\left(\operatorname{HEIGHT}_{w}(S)=d^{\prime}\right)= \\
& \operatorname{HEIGHT}_{w}(J)>_{\text {tall }} \operatorname{HEIGHT}_{w}(S)
\end{aligned}
$$

In a definite-style analysis the comparison operation is assumed to be expressed by the comparative morpheme. A sample lexical entry is given in (17). '-er' combines with a gradable predicate $A$ and a standard of comparison degree $d$ contributed by the comparative complement to yield a property holding of entities whose degree of $A$-ness exceeds $d$ on a relevant scale. ${ }^{2}$

$$
\llbracket \text {-er } \rrbracket=\lambda w \lambda A_{d(e t)} \lambda d \in F\left(>_{R}\right) \lambda x_{e} \iota d^{\prime}\left(A\left(d^{\prime}\right)(x)\right)>_{R} d
$$

'Than'-clauses are assumed to undergo ellipsis, known as comparative deletion since the work of Bresnan (1973), see (18-a). After reconstruction, the question word is moved from the degree argument position of the adjective to the edge of the clause and is interpreted as a lambda abstractor. As a result, the comparative complement denotes a property of degrees. This property is coerced into a degree description by a covert definite term, as outlined in (18-b).

$$
\begin{aligned}
& \text { a. } \quad \text { than Sam is how tall } \\
& \text { b. } \quad \llbracket \operatorname{DEF}[\lambda d \text { Sam } d \text { tall }] \rrbracket=\lambda w \iota d\left(\operatorname{HEIGHT}_{w}(S)=d\right)
\end{aligned}
$$

Let us now consider how an analysis along these lines is applied to (19) below. To this end, I give a lexical entry for 'short' in (20-a). 'Short' is assumed to employ the same measure function as its positive polar antonym 'tall'. This amounts to postulating that equivalence classes formed by the relation $\approx_{\text {short }}$ are identical to those formed by the relation $\approx_{\text {tall }}$. Shortness degrees are therefore indistinguishable from tallness degrees. They are, however, associated with a different ordering. This ordering is based on the basic relation $\succ_{\text {short }}$ which is the inverse

[2] The analysis is couched in an intensional framework in the style of Heim \& Kratzer (1998), which I adopt throughout this paper. 
of the $\succ_{\text {tall }}$. Given this definition of 'short', the analysis of (19) proceeds along the lines in (20-b). The sentence is predicted true in $w$ iff Sam's height exceeds Judy's on the shortness scale, i. e. iff Sam belongs to the class of people who are judged shorter than those to whom Judy belongs.

(19) Sam is shorter than Judy is.

(20) a. $\llbracket$ short $\rrbracket=\lambda w \lambda d \in F\left(>_{\text {short }}\right) \lambda x \operatorname{HEIGHT}_{w}(x)=d$

b. $\quad \llbracket-e r \rrbracket(w)(\llbracket \operatorname{short} \rrbracket(w))\left(\operatorname{HEIGHT}_{w}(J)\right)(S)=$

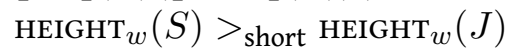

Given degrees as equivalence classes, which constitute ordinal scales, we still do not have a means to treat expressions like (21), where the notion of distance plays a crucial role. Degrees based on equivalence classes cannot be used to measure distance. The interpretation of the subcomparative in (22) appears even more involved. We cannot apply the analysis sketched above to (22), for we cannot directly relate a width degree to a length degree. Intuitively, we seem to be comparing two measures here, not simply two equivalence classes of individuals.

(21) a. Judy is $5 \mathrm{~cm}$ taller than Sam is.

b. Judy is $1.80 \mathrm{~m}$ tall.

(22) The doorway is wider than the shelf is long.

The standard method to handle measures is to replace an ordinal system of measurement induced by degrees by an interval system of measurement, see Klein (1991) and von Stechow (2008). For this purpose, an operation of addition is defined on degrees via some operation of fusion on individuals in their domain. For degrees of length such operation is concatenation, see (23). Given addition, it is possible to define multiplication of degrees as shown in (24).

(23) Assume that $\circ$ is an operation of concatenation on the domain of individuals. Let $d, d^{\prime} \in D_{\text {tall }}$. $d+d^{\prime}=\left\{u: u \in F\left(\succ_{\text {tall }}\right) \wedge \exists x \in d, \exists y \in d^{\prime}: x \circ y=u\right\}$

(24) For any degree $d$ the following holds: $2 d=d+d \wedge n d=(n-1) d+d$

The sequence $d, 2 d, 3 d \ldots$ is called a standard sequence based on $d$ in Krantz et al. (1971). The notion of standard sequence is used in semantics to define measure expressions. A standard sequence can be based on a unit of measurement. First, we construct a degree corresponding to the equivalence class of entities that are exactly as tall as a meter unit object. Call this degree $[\mathrm{m}]_{\text {tall }}$. The standard sequence that is based on $[\mathrm{m}]_{\text {tall }}$ looks as follows: $[\mathrm{m}]_{\text {tall }}, 2[\mathrm{~m}]_{\text {tall }}, 3[\mathrm{~m}]_{\text {tall }} \ldots$. Expressions, like ' 2 meter' are usually assumed to refer to the members of that sequence. Once fractions are defined, ' 1.80 meter' can be analysed as referring to the degree 
$1.8[\mathrm{~m}]_{\text {tall }}$. The analysis of the measure phrase construction in $(21-\mathrm{b})$ is straightforward, see (25).

$$
\operatorname{HEIGHT}_{w}(J)=1.8[m]_{\text {tall }}
$$

Differentials are usually analysed as measures of distance between two degrees. Distance between two degrees can be defined as in (26-a). To handle (21-a) let us assume with von Stechow (2008) that '(by) $5 \mathrm{~cm}$ ' is composed with the comparative morpheme and adds a measure of distance to the operation of comparison, as shown in (26-b). The truth conditions of (21-a) are computed in (27).

$$
\begin{aligned}
& \text { a. } \quad \forall d, d^{\prime} \operatorname{DiSTANCE}_{R}\left(d, d^{\prime}\right)=\iota d^{\prime \prime} \in F\left(>_{\mathrm{R}}\right), \\
& \quad \text { such that } d+d^{\prime \prime}=d^{\prime} \vee d^{\prime}+d^{\prime \prime}=d \\
& \text { b. } \quad \llbracket 5 \mathrm{~cm} \rrbracket=\lambda w \lambda O_{(d(e t))(d(e t))} \lambda A_{d(e t)} \lambda d_{d} \in F\left(>_{R}\right) \lambda x_{e} O(A)(d)(x) \\
& \quad \wedge \operatorname{DiSTANCE}_{R}\left(d, \iota d^{\prime}\left(A\left(d^{\prime}\right)(x)\right)\right)=5[\mathrm{~cm}]_{R} \\
& \llbracket 5 \mathrm{~cm} \rrbracket(w)(\llbracket-\operatorname{er} \rrbracket(w))(\llbracket \operatorname{tall} \rrbracket(w))\left(\operatorname{HEIGHT}_{w}(S)\right)(J) \\
& =\llbracket-\operatorname{er} \rrbracket(w)(\llbracket \operatorname{tall} \rrbracket(w))\left(\operatorname{HEIGHT}_{w}(S)\right)(J) \\
& \wedge \operatorname{DISTANCE}_{\text {tall }}\left(\operatorname{HEIGHT}_{w}(S)\right), \iota d^{\prime}\left(\llbracket \operatorname{tall} \rrbracket(w)\left(d^{\prime}\right)(J)\right)=5[\mathrm{~cm}]_{\text {tall }} \\
& =\operatorname{HEIGHT}_{w}(J)>_{\text {tall }} \operatorname{HEIGHT}_{w}(S) \\
& \wedge \operatorname{DISTANCE}_{\text {tall }}\left(\operatorname{HEIGHT}_{w}(S), \operatorname{HEIGHT}_{w}(J)\right)=5[\mathrm{~cm}]_{\text {tall }}
\end{aligned}
$$

I close this section by sketching an analysis of the subcomparative in (22). Following von Stechow, let us assume that in such cases the comparative may abstract from dimension and relate two degree quantities, i. e. to avoid undefinedness in (28-a) we opt for the meaning of the comparative in (28-b).

$$
\begin{array}{ll}
\text { a. } & \operatorname{WIDTH}_{w}(\text { door })>>_{\text {long }} \mathrm{LENGTH}_{w}(\text { shelf }) \\
\text { b. } & \llbracket-e r \mathrm{QU} \rrbracket=\lambda w \lambda A_{d(e t)} \lambda d_{d} \lambda x_{e} \mathrm{QU}\left(\iota d^{\prime}\left(A(w)\left(d^{\prime}\right)(x)\right)\right)>\mathrm{QU}(d), \\
& \text { where for relation } A \text {, unit of measurement } u \text { and degree } d=n[u]_{A}: \\
& \mathrm{QU}(d)=n[u]
\end{array}
$$

\section{[3] POLARITY EFFECTS}

\section{[3.1] The problem of polar (a)nomalies}

Most asymmetries between negatively and positively polar adjectives (henceforth $\mathrm{A}-$ and $\mathrm{A}+$ ) I touched upon at the outset of the paper follow from the treatment of antonyms outlined in the previous section. As von Stechow (2008) observes, we cannot define multiples of negative degrees. For example, $1.8[\mathrm{~m}]_{\text {short }}$ has to be 1.8 times more short than $[\mathrm{m}]_{\text {short }}$. In order to make sense of this, we would need to define an operation of addition $+_{\text {short }}$, such that for two shortness degrees $d$ and $d^{\prime}$ the following would hold: $d+_{\text {short }} d^{\prime}>_{\text {short }} d$. There seems to be no natural way to do that. As a result, (29-a) and (30-a), whose semantics is based on the operation of multiplication, come out undefined. 
a. ??Judy is $1.80 \mathrm{~m}$ short.

b. $\operatorname{HEIGHT}_{w}(J)=1.8[m]_{\text {short }}$

undef!

a. ??Sam is twice as short as Judy.

b. $\operatorname{HEIGHT}_{w}(S)=2 n[u]_{\text {short }}$, for some unit $u$ and $n[u]_{\text {short }}=\operatorname{HEIGHT}_{w}(J)$

Importantly, since measures of distance always refer to positive degrees, measure phrases are correctly predicted to be acceptable in comparatives with A-, cf. (31).

a. Sam is $5 \mathrm{~cm}$ shorter than Judy is.

b. $\operatorname{HEIGHT}_{w}(S)>_{\text {short }} \operatorname{HEIGHT}_{w}(J) \wedge \operatorname{DISTANCE}_{\text {short }}\left(\operatorname{HEIGHT}_{w}(S)\right.$, $\left.\operatorname{HEIGHT}_{w}(J)\right)=5[\mathrm{~cm}]_{\text {short }}$

What remains unaccounted for is the pattern of cross-polar comparisons in (32-a) and (32-b). Obviously, if a subcomparative contains an A-, we expect it to be deviant, for we cannot abstract a quantity from a negative degree and so the operation QU cannot be applied. This accounts for the deviance of (32-a). However, the acceptability of the cross-polar comparison in (32-b) and the subcomparative with two A- in (32-c) remains unexplained.

a. ??The doorway is higher than the shelf is narrow.

b. The doorway is lower than the shelf is wide.

c. The doorway is lower than the shelf is narrow.

In the following subsection I shall show that an alternative interval-based approach to the analysis of antonyms also fails to account for the problem of crosspolar comparisons.

\section{[3.2] Extents}

Polar anomalies caused a lively debate on the status of degrees in the analysis of comparatives. Following a suggestion by Seuren (1984), von Stechow (1984b) modifies the concept of a degree to account for distinctions between $\mathrm{A}+$ and $\mathrm{A}-$. He proposes that measure functions do not map individuals to discrete points on a relevant scale but to intervals of a special sort, which he calls extents. The differences in the distribution of $\mathrm{A}+$ and $\mathrm{A}-$ can be captured by the distinction between negative and positive extents in the ranges of their measure functions. A positive extent is a convex set of points on a scale that spans from zero to some positive value, whereas a negative extent starts at some positive value and has no upper bound. For example, suppose that Judy is $1.75 \mathrm{~m}$ tall. Her tallness and shortness extents are schematized in (33). 
(33)

$$
\text { [ Judy's tallness ] [ Judy's shortness ) }
$$

Von Stechow represents a positive extent as a pair of the form $<_{A} 0, n>$ and a negative extent as $<_{A} k, \infty>$, where the subscript $A$ indicates dimension. To define antonyms, he introduces a negation operation that turns a positive extent into a negative one, as shown in (34-a). A negative antonym A-denotes a relation between an individual and the negation of a positive extent that is in the domain of the positive antonym $\mathrm{A}+$, see (34-b).

$$
\begin{aligned}
& \text { a. } \neg<_{A} 0, n>:=<_{A} n, \infty> \\
& \text { b. } \mathrm{A}-(x, \neg e) \text { if and only if } \mathrm{A}+(x, e)
\end{aligned}
$$

Von Stechow assumes that measure phrases denote positive extents and therefore they can only be used as names for positive extents, which renders (35-b) below anomalous.
a. Judy is $1.80 \mathrm{~m}$ tall. $\operatorname{TALLNESS}_{w}(J)=<$ height $0,1.80>$
b. ??Judy is $1.80 \mathrm{~m}$ short.$$
\operatorname{SHORTNESS}_{w}(J)=<\text { height } 0,1.80>
$$
undef!

Concatenation or addition is defined for two positive extents and for a positive and a negative extent, as shown in (36).

$$
\begin{aligned}
& \text { a. } \quad<_{A} 0, n>+<_{A} 0, m>=<_{A} 0, n+m> \\
& \text { b. } \quad<_{A} 0, n>+<_{A} m, \infty>=<_{A} m-n, \infty>
\end{aligned}
$$

The comparative is assumed to take a measure of difference as an argument and expresses an operation of concatenation, see (37).

$$
\llbracket \text {-er } \rrbracket=\lambda w \lambda d_{d}^{\prime} \lambda A_{d(e t)} \lambda d_{d} \lambda x_{e} A\left(d+d^{\prime}\right)(x)
$$

It can be shown that measure phrases are acceptable as measures of difference in negatively polar comparatives, like (38-a). Suppose that Judy is $1.80 \mathrm{~m}$ tall. Her shortness extent is then represented by the pair $<_{\text {height }} 1.80, \infty>$. By (36-b), it can be concatenated with a positive extent $<_{\text {height }} 0,0.05>$. The result is a negative extent corresponding to Sam's shortness, see (38-b).

(38) a. Sam is $5 \mathrm{~cm}$ shorter than Judy is.

b. $\operatorname{SHORTNESS}_{w}(S)=\operatorname{SHORTNESS}_{w}(J)+<_{\text {height }} 0,0.05>=$

$$
<_{\text {height }} 1.75, \infty>
$$


The assumption that numerical phrases denote positive extents is crucial. As pointed out in Sassoon (2007), this is problematic for cases like (39-a). Indeed, we cannot obtain Judy's shortness extent by concatenating two positive extents.

a. Judy is $20 \mathrm{~cm}$ shorter than $2 \mathrm{~m}$.

b. $\operatorname{SHORTNESS}_{w}(J)=<$ height $0,2>+<0,0.2>$

undef!

This problem is inherited by Kennedy (1997) who also endorses a sortal distinction between negative and positive degrees by defining them as Seuren's extents. As a remedy, Kennedy suggests that measure phrases might have different denotations. Whereas ' $1.80 \mathrm{~m}$ ' in the measure phrase constructions in (35-a) denotes a positive extent, ' $2 \mathrm{~m}$ ' in the comparative in (39-a) denotes an entity which is mapped by the measure function of 'short' to a negative extent.

Cross-polar comparisons present another problem for the extent-based analysis. The A+/A- comparative in (40) is effectively ruled out: concatenating Sam's shortness with a positive extent can produce only a negative extent, which does not correspond to Judy's tallness. Obviously, the same result could be derived for two-dimensional comparatives like (32-a) if we can find a way to abstract away from the dimension. A-/A- comparatives like (32-c) would be correctly predicted to be grammatical. The problem resides in cross-polar nomalies like (32-b), i. e. comparatives of the form A+/A-. As cross-polar comparisons, they come out deviant, contrary to the intuitive judgment.

(40) ??Judy is taller than Sam is short.

The idea of extents has remained influential for over more than two decades. One of its implementations due to Heim (2001) is adopted in many mainstream analyses of degree constructions. Heim assumes that gradable adjectives, which have a relational meaning, denote monotone functions in the following sense: a function $f$ denoting a relation between an individual and a degree is monotone if and only if for any two degrees $d$ and $d^{\prime}$ and individual $x$, if $f$ is true of $x$ and $d$ and $d>d^{\prime}$ then $f$ is true of $x$ and $d^{\prime}$ :

$$
\forall d, d^{\prime} \in D_{d}, f \in D_{d(e t)}, x \in D_{e}:\left(d>d^{\prime} \wedge f(x, d)\right) \rightarrow f\left(x, d^{\prime}\right)
$$

A sample lexical entry in (42) defines 'tall' as a function with the property in (41). According to (42), 'tall' applied to an individual $x$ denotes a set of degrees that are smaller or equal to $x$ 's height. Put differently, $x$ is related to an interval on the scale of tallness degrees that stretches from the lower end of the scale to the height of $x$, which corresponds to the positive extent of $x$ 's tallness.

$$
\llbracket \text { tall } \rrbracket=\lambda w \lambda d \lambda x \operatorname{HEIGHT}_{w}(x) \geq d
$$


In Heim (2004), a negative antonym is defined as the internal negation of its positive counterpart, cf. (43-a) and (43-b). A- relates an individual $x$ to the negation of the extent that $x$ is related to by $\mathrm{A}+$, see $(43-\mathrm{c})$.

$$
\begin{aligned}
& \text { a. Adjectival negation: } \operatorname{LittLe}\left(A_{d(e t)}\right)=\lambda d \lambda x \neg A(d)(x) \\
& \text { b. } A-:=\operatorname{LitTLE}(A+) \\
& \text { c. } \quad \llbracket \operatorname{SHORT} \rrbracket=\lambda w \lambda d \lambda x \operatorname{HEIGHT}_{w}(x) \prec d
\end{aligned}
$$

This analysis of antonyms is known as "negation theory of antonymy". Heim does not address the licensing of numerical modifiers in Heim (2001). A possible solution to this problem under the negation theory is sketched in (von Stechow 2006). Von Stechow proposes to type-lift measure expressions to the quantifier meaning as shown in (44-a) for ' $1.80 \mathrm{~m}$ '. ' $1.80 \mathrm{~m}$ ' is true of a set of degrees whose maximum is at least $1.80 \mathrm{~m}$.

(44) a. $\quad \llbracket 1.80 \mathrm{~m} \rrbracket=\lambda w \lambda D_{d t} \operatorname{MAX}(D) \geq 1.80 \mathrm{~m}$, where MAX is defined below. b. $\operatorname{MAx}\left(D_{d t}\right)=\iota d: d \in D \wedge \forall d^{\prime} \in D: d^{\prime} \leq d$

Assuming that the tallness scale is open-ended, (35-b) repeated in (45-a) below comes out undefined under this analysis.

$$
\begin{aligned}
& \text { a. *Judy is } 1.80 \mathrm{~m}_{\text {short. }} \\
& \text { b. } \operatorname{MAX}\left(\lambda d \operatorname{HEIGHT}_{w}(J)<d\right) \geq 1.80 \mathrm{~m}
\end{aligned}
$$

undef!

The account of the cross-polar anomaly in (40) depends on the treatment of the comparative. In Heim (2007), '-er' expresses the inclusion relation between two sets of degrees formed by abstracting over the degree arguments of the main predicate and the reconstructed embedded predicate, see (46-a). Obviously, crosspolar comparisons can never be true in this analysis, which may be seen as a reason for their deviance, see (46-b). However, the asymmetry between $A-/ A+$ and $\mathrm{A}+/ \mathrm{A}-$ still remains a puzzle.

$$
\begin{array}{ll}
\text { a. } & \llbracket \text {-er } \rrbracket=\lambda w \lambda D_{d t} \lambda D_{d t}^{\prime} D \subseteq D^{\prime} \\
\text { b. } & {\left[\lambda d \operatorname{HEIGHT}_{w}(S)<d\right] \subseteq\left[\lambda d \operatorname{HEIGHT}_{w}(J) \geq d\right]}
\end{array}
$$

To conclude, though a standard theory of antonyms derives some polar anomalies, such as the ungrammaticality of measure phrase constructions with $\mathrm{A}-$, it does not account for the cross-polar paradigm. Theories based on a shift to intervals inherit this problem.

\section{[3.3] Cross-polar paradigm revisited}

Bierwisch (1989) gives an accurate and exhaustive survey of the anomaly pattern of subdeletion comparatives. He discusses subdeletion paradigms for comparatives and equatives in German, which appear to differ in their acceptability pat- 
terns, see (47) and (48).

(47) a. Der Tisch ist höher als er breit ist. the table is higher than it wide is 'The table is higher than it is wide.'

b. ?Der Tisch ist niedriger als er breit ist. the table is lower than it wide is 'The table is lower than it is wide.'

c. ?Der Tisch ist niedriger als er schmal ist. the table is lower than it narrow is 'The table is lower than it is narrow.'

d. ??Der Tisch ist höher als er schmal ist. the table is higher than it narrow is 'The table is higher than it is narrow.'

(48) a. Der Tisch ist so hoch wie er breit ist. the table is that high how it wide is 'The table is as high as it is wide.'

b. ?Der Tisch ist so niedrig wie er breit ist. the table is that low how it wide is 'The table is as low as it is wide.'

c. Der Tisch ist so niedrig wie er schmal ist. the table is that low how it narrow is 'The table is as low as it is narrow.'

d. ?Der Tisch ist so hoch wie er schmal ist. the table is that high how it narrow is 'The table is as high as it is narrow.'

According to Bierwisch, (47-a) and (47-b) can relate two length degrees directly, (47-c) and (47-d) cannot express regular comparison but only allow for what he calls a secondary N-reference reading. He gives the following paraphrase for (47-c).

(49) The table is further below the contextual norm regarding height than regarding width.

Bierwisch characterizes the acceptability pattern in (47)-(48) in the following way. Negative polar adjectives are generally impossible in comparative complements. If a negative predicate occurs in a 'than' clause of a subdeletion comparative, the secondary $\mathrm{N}$-reference interpretation obtains. It requires setting up an auxiliary scale different from the degree scale used for making direct comparisons, which amounts to a re-interpretation step, hence the markedness of (47-c) and (47-d). In equatives, there is no ban on negative polarity in the complement. 
In an $\mathrm{A}-/ \mathrm{A}-$ equative, like (48-c), $\mathrm{N}$-reference is not secondary. It must have the same source as a norm-related interpretation of A- equatives, e.g. (50).

(50) Der Tisch ist so niedrig wie das Bett.

the table is that low how the bed

'The table is as low as the bed.'

Another factor that adds to the deviancy of (47-d) and reduces the acceptability of (47-b) and the equatives in (48-b) and (48-d) is scale reversal, i. e. opposite polarity of the involved predicates.

That a regular comparison interpretation is impossible in (47-c) and (47-d) is supported by the fact that they disallow differential measure phrases, see (51).

a. *Der Tisch ist $10 \mathrm{~cm}$ niedriger als er schmal ist. the table is $10 \mathrm{~cm}$ lower than it narrow is 'The table is $10 \mathrm{~cm}$ lower than it is narrow.'

b. *Der Tisch ist $10 \mathrm{~cm}$ höher als er schmal ist. the table is $10 \mathrm{~cm}$ higher than it narrow is 'The table is $10 \mathrm{~cm}$ higher than it is narrow.'

For the equatives in (48) modifiability by ratio modifiers can be used to test the availability of a regular comparison. As shown in (52), 'twice' is ruled out in the examples that Bierwisch characterises as norm-related.

(52) a. Der Tisch ist doppelt so hoch wie er breit ist. the table is twice that high how it wide is 'The table is twice as high as it is wide.'

b. *Der Tisch ist doppelt so niedrig wie er breit ist. the table is twice that low how it wide is Lit: 'The table is twice as low as it is wide.'

c. *Der Tisch ist doppelt so niedrig wie er schmal ist. the table is twice that low how it narrow is Lit: 'The table is twice as low as it is narrow.'

d. *Der Tisch ist doppelt so hoch wie er schmal ist. the table is twice that high how it narrow is Lit: 'The table is twice as high as it is narrow.'

Given Bierwisch's paradigm and its apparent applicability to English, see Kennedy (2001), ${ }^{3}$ a theory that aims to account for markedness of A-, has to address the following questions:

[3] Although Kennedy disagrees with Bierwisch on the status of A-/A- comparatives, his examples of a regular comparison reading of $\mathrm{A}-/ \mathrm{A}-$ comparatives are exceptional and can be categorized as word play. 
(53) Why does the asymmetry of poles not lead to anomaly in A+/A- comparatives?

(54) Why do A-/A - comparatives and equatives disallow measure phrases despite the symmetry of the poles?

Obviously, the extent-based approaches face difficulties with the cases where one cannot appeal to the asymmetry of the poles on the one hand, e.g. (51-a), and where this asymmetry does not lead to unacceptability on the other, e.g. (47-b). Differences in the licensing of numerical modifiers in comparatives and equatives present an additional complication which has to be dealt with by any theory of antonymy.

Question (53) has not been addressed by the extent-based theories to the best of my knowledge. Norm-relatedness of subdeletion comparatives and equatives as well as degree questions with negative adjectives is not regarded as noteworthy. Kennedy (2001) proposes that comparison with a contextual norm is sometimes triggered by a special status of $\mathrm{A}-$. As marked members of antonym pairs, negative adjectives carry a presupposition that "the property they describe does hold of the target of predication". Thus, (55-a) and (55-b) are only felicitous in a context in which the table is low. In (55-a) it is additionally presupposed to be narrow. However, it is unclear why this requirement does not apply in (55-c) which seems perfectly neutral in this respect.

(55) a. The table is lower than it is narrow.

b. How low is the table?

c. The table is lower than the bed.

On the other hand, question (54) attracted quite some attention in the recent literature. Büring (2007) and Heim (2008) discuss the acceptability of cross-polar nomalies from the perspective of the negation theory. I turn to their accounts in the following section.

\section{[3.4] Accounts of cross-polar nomalies}

Kennedy (2001) notes that A+/A- comparatives are degraded in English unless the adjectives involved are associated with different dimensions, cf. (56). The same point is made in Büring (2007) where two-dimensional A-/A+ comparatives like (56-b) are called cross-polar nomalies, while A-/A+ comparatives with the adjectives sharing the dimension, like (56-a), are categorized as cases of crosspolar anomaly.

(56) a. ?The ski poles are shorter than the box is long.

b. The ski poles are shorter than the box is wide. 
Büring (2007) argues that $\mathrm{A}-/ \mathrm{A}+$ comparatives are possible because abstract negation (LITTLE) on a A- can split from the adjective and attach to the comparative morpheme, i. e. LITTLE-A-er can be interpreted as LITTLE-er A. To make this concrete, 'shorter' is assumed to be sometimes interpreted as 'less tall'. This decomposition step, apparently inspired by the discussion of 'less' comparatives in Rullmann (1995), allows one to do away with cross-polarity and treat surface A-/A+ comparatives as underlying $\mathrm{A}+/ \mathrm{A}+$ ones.

The difference in the acceptability of two-dimensional and one-dimensional $\mathrm{A}-/ \mathrm{A}+$ comparatives does not immediately follow on this approach. The latter are predicted to be interpretable if LITTLE is bracketed with the comparative. However, as Büring argues, though this construal is possible, the deletion of the entire embedded AP is preferred in such cases over the deletion of the degree morphology, that is, comparative deletion is preferred over subdeletion. As a result, one-dimensional A-/A + comparatives are unacceptable for most speakers.

Some consequences of Büring's proposal are discussed in Heim (2008) where Büring-style decomposition is characterized as a syntactic negation theory of antonymy. Such an approach presupposes that the lexicon does not contain entries for negative adjectives. Words like 'short' are spell outs of two units: a positively polar adjective and a predicate negation. The negation unit appears in the prespell-out representations of 'less' and negatively polar adjectives.

This approach is to be distinguished from a lexical theory of antonymy adopted by Heim (2007), where A - are assumed to be listed as separate meaningful units in the lexicon on the par with A+. In contrast to Büring's analysis, no part of the syntactic representation of A- corresponds to a predicate negation.

To account for cross-polar nomaly, Heim (2008) follows the path laid down by Büring. She assumes that despite the cross-polar surface realisation of such sentences, on the level of LF they involve two comparable predicates, that is, two predicates with matching polarity. This is achieved by analysing A- as a spell out of an immobile LITTLE and the corresponding A+ and positing a covert LITTLE in the complement clause. The process of comparative deletion should take care of this case and erase the embedded instance of LITTLE. As a result, both predicates are A-, i. e. they map their individual-denoting arguments to negative extents. Though forced to decompose negative predicates, Heim emphasises that her analysis does not treat 'shorter' by analogy with 'less tall.' She posits two separate kinds of LitTLE. The first one, which is responsible for the formation of antonyms, is always bracketed with the adjective at the logical form, whereas the second one, spelling out 'less' and semantically distinct from the antonymforming LITTLE, is a scopally active element.

Assessing her proposal, Heim admits that positing a silent LITTLE is driven by the need to account for the acceptability of A-/A+ comparatives. Apart from not being motivated independently, this move inevitably leads to the complication of 
the theory of ellipsis.

\section{[4] SCALARITY AND N-REFERENCE}

In this section I lay out an extension of a standard degree-based analysis of comparatives sketched in section [2] and argue that it meets the challenges of existing theories of antonyms. I start with a new approach to measures in section [4.1]. In section [4.2] I derive the distribution of N-reference and its correlation with the licensing of measure phrases. In section [4.3] I apply the analysis to Russian.

\section{[4.1] Measures}

There is a way to deal with measures that does not require that addition and multiplication be defined on degrees. Those operations may be performed on real numbers to which some degrees may be mapped by an appropriately defined numerical assignment. I sketch such a method below.

I start by introducing a class of parametrised functions from degrees of a particular sort to real numbers. Call such functions $\mathrm{NUM}_{u, R}$ where the indices correspond to a unit of measurement and a dimension, respectively. For example, $\mathrm{NUM}_{\text {meter, tall }}$ maps a height degree $d$ to a real number that represents the ratio between an entity from the domain of $d$ and an entity from the equivalence class of a meter unit object $m$.

$$
\begin{aligned}
& \forall d \in F\left(\succ_{\text {tall }}\right): \operatorname{NUM}_{\text {meter,tall }}(d)=\iota n \text {, such that } \exists y \in[m]_{\text {tall }} \exists x \in d: \\
& x / y=1 / n
\end{aligned}
$$

By the same token, we may define a function that maps a weight degree to its ratio to a standard represented by weight measures, such as kilo, and so on. Finding a ratio between two entities is fundamental to a system of measurement. The idea is simple. For example, to determine the ratio representing the length of a desk in meters we apply a meter unit object, say, a meter long ruler, and if necessary its parts, to the longer side of the desk and find out how many times we need to repeat this procedure to cover the entire length of the desk.

Given this kind of homomorphism into real numbers, which can be applied at LF whenever required, the simple notion of a degree as an equivalence class inducing an ordinal scale is preserved. Let me demonstrate how constructions (21)-(22) are handled in this approach. I start with the measure phrase construction in (21), repeated below.

$$
\text { Judy is } 1.80 \mathrm{~m} \text { tall. }
$$

I assume that the head of the measure phrase ' $1.80 \mathrm{~m}$ ' is an operator that turns a number and a name of unit into a degree, as defined in (59). In the example at hand, EQ maps the number 1.80 and the unit name 'meter' to the height de- 
gree to which the function $\mathrm{NUM}_{\text {meter,tall }}$ assigns 1.80 . The entire LF of (58) and its interpretation are given in (59-b).

$$
\begin{array}{ll}
\text { a. } & \operatorname{EQ}(n)(u)=\iota d \in F\left(>_{R}\right): \operatorname{NUM}_{u, R}(d)=n \\
\text { b. } & \llbracket \operatorname{tall} \rrbracket(\mathrm{w})(\mathrm{EQ}(1.80)(\text { meter }))(J)= \\
& \operatorname{HEIGHT}_{w}(J)=\iota d \in F\left(>_{\text {tall }}\right): \mathrm{NUM}_{\text {meter,tall }}(d)=1.8
\end{array}
$$

The analysis of the differential in (21-a), repeated in (60), is parallel to that of von Stechow (2008), cf. (61-b).

(60) Judy is $5 \mathrm{~cm}$ taller than Sam is.

I redefine DISTANCE to incorporate a NUM function. DISTANCE maps two degrees to the distance between their numerical values, see (61-a).

$$
\begin{array}{ll}
\text { a. } & \forall d, d^{\prime} \in F\left(\succ_{R}\right): \operatorname{Distance}\left(d, d^{\prime}, u\right)=\left|\operatorname{NUM}_{u, R}(d)-\operatorname{NUM}_{u, R}\left(d^{\prime}\right)\right| \\
\text { b. } & \llbracket 5 \mathrm{~cm} \rrbracket=\lambda w \lambda O_{(d(e t))(d(e t))} \lambda A_{d(e t)} \lambda d_{d} \lambda x_{e} O(A)(d)(x) \\
& \wedge \operatorname{Distance}\left(d, \iota d^{\prime}\left(A\left(d^{\prime}\right)(x)\right), \mathrm{cm}\right)=5
\end{array}
$$

Finally, to treat subdeletion comparatives, like those in (22) repeated below in (62), I define a new variant of the comparative morpheme which applies in cases of two-dimensional comparisons. The resulting truth conditions of (62-a) are given in $(62-c)$.

$$
\begin{aligned}
& \text { a. The doorway is wider that the shelf is long. } \\
& \text { b. } \llbracket-\mathrm{er}^{\mathrm{NUM}} \rrbracket=\lambda w \lambda A_{d(e t)} \lambda d_{d} \lambda x_{e} \mathrm{NUM}_{u}\left(\iota d^{\prime}\left(A\left(d^{\prime}\right)(x)\right)\right)>_{R} \mathrm{NUM}_{u}(d) \text {, } \\
& \text { where }>_{R} \text { is a ' }>\text { ' or ' }<\text { ' ordering on real numbers. } \\
& \text { c. } \operatorname{NUM}_{u, \text { long }}\left(\operatorname{WIDTH}_{w}(d)\right)>\operatorname{NUM}_{u, \text { long }}\left(\operatorname{LENGTH}_{w}(s)\right)
\end{aligned}
$$

I assume that the polarity of the adjective argument determines which ordering is employed by -er ${ }^{\mathrm{NUM}}$; $\mathrm{A}+$ leading to the choice of ' $>$ ' and A-to the choice of ' $<$ '. This analysis predicts that the polarity of the embedded adjective does not have any impact on the truth conditions, see (63). NUM maps a negative polar degree to the same value it maps the respective positive polar degree to, because they correspond to one and the same equivalence class.

(63) a. The doorway is wider that the shelf is long/??short.

$$
\operatorname{NUM}_{u, \text { wide }}\left(\operatorname{WIDTH}_{w}(d)\right)>\mathrm{NUM}_{u, \text { long/short }}\left(\operatorname{LENGTH}_{w}(s)\right)
$$

b. The doorway is shorter than the shelf is wide/??narrow.

$$
\operatorname{NUM}_{u} \text { long }\left(\operatorname{LENGTH}_{w}(d)\right)<\operatorname{NUM}_{u, \text { wide/narrow }}\left(\operatorname{LIDTH}_{w}(s)\right)
$$

Another construction whose semantics incorporates a function NUM is the equative with a ratio modifier, like (64-a). I assume that an equative complement is a correlative clause that provides the value for the correlate 'as' in the matrix 
clause. For reasons of space I do not spell out its composition. For the present purpose, suffice it to say that the degree argument of the matrix adjective is saturated by the correlate. Provided that the value of the correlate in (64-a) is set to the height of the shelf, the sentence without 'twice' is predicted to be true in $w$ iff the height of the shelf in $w$ equals the height of the doorway in $w$, see (64-b).
a. The doorway is (twice) as high as the shelf.
b. $\operatorname{HEIGHT}_{w}(d)=\operatorname{HEIGHT}_{w}(s)$

'Twice' applies to the correlate and doubles the numerical value of the degree it refers to, as shown in (65).

$$
\begin{array}{ll}
\text { a. } & \llbracket \text { twice } \rrbracket=\lambda w \lambda d \in F\left(>_{R}\right) \iota d^{\prime}\left(2 \operatorname{NUM}_{u, R}(d)=\operatorname{NUM}_{u, R}\left(d^{\prime}\right)\right) \\
\text { b. } & \operatorname{HEIGHT}_{w}(d)=\iota d^{\prime}\left(2 \operatorname{NUM}_{u, R}\left(\operatorname{HEIGHT}_{w}(s)\right)=\operatorname{NUM}_{u, R}\left(d^{\prime}\right)\right)
\end{array}
$$

In subdeletion equatives, the same operation of accomodation is at work as in subdeletion comparatives, i. e. the comparison of numerical values of sortally different degrees based on the same unit of measurement.

(66) a. The doorway is as high as the shelf is long.

b. $\operatorname{NUM}_{u, \operatorname{high}}\left(\operatorname{HEIGHT}_{w}(d)\right)=\operatorname{NUM}_{u, \text { long }}\left(\operatorname{LENGTH}_{w}(s)\right)$

In the following section, the current predictions of the analysis will be embedded in a theory of semantic competition between positive and negative adjectives to derive polarity effects.

\section{[4.2] Ambiguity and competition}

In a degree-based approach, it is a common practice to treat positive forms of gradable predicates as expressing comparison with an implicit contextually provided norm, see Cresswell (1976). For example, (67) would be analysed as involving a covert degree morpheme [pos] carrying a 'standard of comparison' variable that applies to 'tall' and turns it into the comparative property in (67-b).
a. Judy is tall.
b. $\quad \llbracket \operatorname{pos}_{\mathrm{c}}$ tall $\rrbracket=\lambda w \lambda x \operatorname{HEIGHT}_{w}(x) \succ g(c)$, where $g(c)$ is a contextual norm for tallness.

I pursue a different approach to the analysis of vague predicates like 'tall' in (67). I treat the positive 'tall' and 'short' as properties of individuals, i.e. as functions of type et, that hold of $x$ iff $x$ is considered tall and short, respectively, in the given context, see (68).

$$
\begin{aligned}
& \text { a. } \quad \llbracket \text { tall } \rrbracket=\lambda c \lambda x x \in \operatorname{pos}_{\text {tall }}(c) \\
& \text { b. } \llbracket \text { short } \rrbracket=\lambda c \lambda x x \in \operatorname{pos}_{\text {short }}(c)
\end{aligned}
$$


There are various ways to account for the vagueness of 'tall' in (67), see Klein (1980) for a related discussion. I assume that vagueness is a result of the blurred, i.e. unknown, boundary between the positive and the negative extension of a gradable predicate.

Under the present view, gradable adjectives are lexically ambiguous between a scalar relational meaning and a predicate meaning. The presence of degree morphology and measure phrases requires scalar meanings. Drawing on a proposal in Rett (2008) I suggest that there is an additional factor that may restrict the choice of a scalar meaning, namely semantic competition between $\mathrm{A}+$ and A-. The crucial idea of Rett's theory is that competition arises between two semantically equivalent sentences differing only in the polarity of the predicates. It results in a re-interpretation of sentences featuring negative polar adjectives. In the current approach, re-interpretation may be conceived as the choice of a non-scalar meaning. This factor is ultimately responsible for the observed polar asymmetry in English. Let me spell out this process in detail.

Assume that A- elements of antonym pairs are marked relative to their $\mathrm{A}+$ counterparts. This assumption - though a stipulation at this point - is most probably related to the nature of the empirical relation used for forming equivalence classes of negative and positive polar degrees. ${ }^{4}$ Then the process of semantic competition can be described as follows:

(69) If two degree constructions $X(\mathrm{~A}-)$ and $X(\mathrm{~A}+)$ can be truth-conditionally equivalent, the speaker only chooses to utter the marked $X(\mathrm{~A}-)$ if she can employ the meaning of $\mathrm{A}-$ that renders $X(\mathrm{~A}-)$ and $X(\mathrm{~A}+)$ nonsynonymous.

Under the assumptions I layed out in the previous section, there are several constructions where competition arises. First, polarity of an adjective does not influence truth conditions of an equative, as shown in (70).

(70) Equative

a. The desk is as $\checkmark$ high/low as the shelf.

b. $\operatorname{HEIGHT}_{w}(d)=\operatorname{HEIGHT}_{w}(s)$

As already pointed out in the previous section, NUM returns the same value for positive and negative antonymous degrees. This results in six pairs of constructions competing with each other, see (71)-(76).

(71) Measure phrase constructions

[4] Surely, constructing Judy's height by means of ' $\succ_{\text {short }}$ ' can be shown to be a cognitively different process from constructing her height by means of the positive polar relation ' $\succ_{\text {tall }}$. The investigation of this issue is beyond the scope of this work. 
a. Judy is $1.80 \mathrm{~m} \checkmark$ tall/short.

b. $\operatorname{HEIGHT}_{w}(J)=\iota d\left(\mathrm{NUM}_{\text {meter,tall/short }}(d)=1.8\right)$

(72) Subdeletion comparatives $\mathrm{A}+/ \mathrm{A}+$ vs. $\mathrm{A}+/ \mathrm{A}-$

a. The desk is higher than it is $\checkmark$ wide/narrow.

b. $\operatorname{NUM}_{u, \text { high }}\left(\operatorname{HEIGHT}_{w}(d)\right) \succ \operatorname{NUM}_{u, \text { wide/narrow }}\left(\operatorname{WIDTH}_{w}(d)\right)$

(73) Subdeletion comparatives $\mathrm{A}-/ \mathrm{A}+$ vs $\mathrm{A}-/ \mathrm{A}-$

a. The desk is lower than it is $\checkmark$ wide/narrow.

b. $\operatorname{NUM}_{u, \text { low }}\left(\operatorname{HEIGHT}_{w}(d)\right) \prec \operatorname{NUM}_{u \text {, wide/narrow }}\left(\operatorname{WIDTH}_{w}(d)\right)$

(74) Subdeletion equatives $\mathrm{A}+/ \mathrm{A}+\mathrm{vs} . \mathrm{A}+/ \mathrm{A}-$

a. The desk is as high as it is $\checkmark$ wide/narrow.

b. $\operatorname{NUM}_{u, \text { high }}\left(\operatorname{HEIGHT}_{w}(d)\right)=\mathrm{NUM}_{u, \text { wide/narrow }}\left(\operatorname{WIDTH}_{w}(d)\right)$

(75) Subdeletion equatives $\mathrm{A}+/ \mathrm{A}+$ vs. $\mathrm{A}-/ \mathrm{A}+$

a. The desk is as $\checkmark$ high/low as it is wide.

b. $\operatorname{NUM}_{u, \text { high/low }}\left(\operatorname{HEIGHT}_{w}(d)\right)=\operatorname{NUM}_{u, \text { wide }}\left(\operatorname{WIDTH}_{w}(d)\right)$

(76) Subdeletion equatives $\mathrm{A}+/ \mathrm{A}+\mathrm{vs}$. $\mathrm{A}-/ \mathrm{A}-$

a. The desk is as $\checkmark$ high/low as it is $\checkmark$ wide/narrow.

b. $\operatorname{NUM}_{u, \text { high } / \text { low }}\left(\operatorname{HEIGHT}_{w}(d)\right)=\operatorname{NUM}_{u, \text { wide/narrow }}\left(\operatorname{WIDTH}_{w}(d)\right)$

The marked construction, i.e. the one with an $\mathrm{A}-$, looses in each case and its adjective is re-interpreted as a predicate of individuals. In the presence of measure phases and ratio modifiers, which require scalar meanings, this results in a derivation crash. Otherwise an N-reference reading in the sense of Bierwisch (1989) obtains. For example, the equative with 'twice' in (77-a) is uninterpretable since the process of semantic competition forces the speaker to employ the predicate meaning of 'short'. If uttered without 'twice' it does not relate Judy's height to Sam's but rather conveys that they are both short relative to the same comparison class. ${ }^{5}$ I propose that N-reference should be viewed as comparison of vague degree adverbials or comparison classes on a conventional scale. Thus, (77-a) without 'twice' is analyzed along the lines in (77-b). The details of the analysis depend on one's assumptions concerning the semantics of vague adverbials or the way in which the comparison class referring expressions like 'for an X', 'compared to X' are treated.

(77) a. Judy is (*twice) as short as Sam.

b. If Sam is fairly/very/extremely short then Mary is fairly/very/ex-

[5] Negative polar equatives are often reported to have a regular comparison reading, however, only in a special kind of context, e.g. in the case of (77) if everyone is considered short. Since such contexts generally obviate polar distinctions one may suppose that semantic competition does not always arise in such cases. 
tremely short too.

\section{[4.3] The case of Russian}

The account of polarity effects presented above is based on a correlation between the distribution of polar anomalies and N-reference. In this section I show that these two phenomena are correlated in a language that does not reveal polarity effects, a correlation which lends additional support to my proposal.

Russian has been observed to lack English-style asymmetries between A- and $\mathrm{A}+$, see Krasikova (2009). Measure phrases are restricted with gradable adjectives in Russian; their distribution is captured by the following generalization: Russian gradable adjectives allow modification by measure phrases only if they bear comparative morphology, see (78).

(78) a. Озеро на $20 \mathrm{~m} /$ в два раза шире реки

lake by $20 \mathrm{~m} /$ in two times wider river-GEN

'The lake is $20 \mathrm{~m}$ wider than the river. / twice as wide as the river.'

b. Озеро *на 20 м/ *в два раза более широкое, чем река

lake by $20 \mathrm{~m} /$ in two times more wide than river

Intended: 'The lake is $20 \mathrm{~m}$ wider than the river. / twice as wide as the river.'

c. Река 20 м шириной/ *широкая

river $20 \mathrm{~m}$ width-INSTR/ wide

'The river is $20 \mathrm{~m}$ wide.'

According to the present analysis measure phrases are licensed only in constructions in which N-reference is optional. Given more stringent rules on licensing of measure phrases, we expect Russian to have a distribution of N-reference different from that observed in English. This prediction is borne out: in Russian $\mathrm{N}$-reference is obligatory with non-comparative adjectives. In effect, any degree construction with a non-comparative adjective conveys comparison with an implicit norm, independent of the polarity of the predicate involved, see (79)-(81).

(79) а. (Мария низкая.) Maria short

b. \#Она такая же высокая, как и Иван./ ${ }^{\text {ok}}$ Она одного роста she that EMPH tall as also Ivan she same height c Иваном with Ivan

'Maria is short. She is as tall as Ivan.'

(80) Белое озеро узкое, но оно \#более широкое, чем Кубенское./ white lake narrow but it more wide than Kubenskoje 
ok шире Кубенского.

wider Kubenskoje-GEN

'The White lake is narrow but it is wider than the Kubenskoje lake.'

(81) Насколько Кубенское озеро широкое?/ Какой ширины Кубенское by how much Kubenskoje lake wide which width Kubenskoje озеро?

lake

'To what extent is the Kubenskoje lake wide?' / 'How wide is the Kubenskoje lake?'

To summarize, Russian gradable adjectives can only be assigned scalar meanings if they are morphologically marked for comparison. Put differently, only adjectives of the form 'A-er' project degrees. Whatever might be the nature of this restriction, it correctly predicts the ban on measure phrases with non-comparative adjectives. Semantic competition between $\mathrm{A}-$ and $\mathrm{A}+$ and, for that matter, polarity effects, does not obtain in Russian.

\section{[5] CONCLUSION}

I argued that the classical degree-based approach to the analysis of degree construction is better equipped to deal with polarity effects in dimensional adjectives than the extent-based theories. Normally, degrees are assumed to constitute interval scales and therefore positive and negative degrees have fundamentally different measurement properties. Treating degrees as simple equivalence classes removes this kind of distinction. Without it, many negative polar constructions in English are truth conditionally equivalent to positive polar ones. The main claim of the paper is that this causes the process of semantic competition and is responsible for polar anomalies. The second claim is that gradable predicates are lexically ambiguous between a scalar and a predicate meaning. The distribution of the two meanings is governed by the occurrence of degree morphology and measure expressions. In English it additionally depends on the outcome of semantic competition. In Russian, scalar meanings are restricted to adjectives in the comparative form and do not compete with predicate meanings.

\section{REFERENCES}

Bierwisch, Manfred. 1989. The semantics of gradation. In Manfred. Bierwisch \& Ewald Lang (eds.), Dimensional adjectives, 71-261. Berlin: Springer- Verlag.

Bresnan, Joan. 1973. Syntax of the comparative clause construction in English. Linguistic Inquiry 4. 275-343. 
Büring, Daniel. 2007. Cross-polar nomalies. In Proceedings of SALT 17, University of Connecticut.

Cresswell, Max J. 1976. The semantics of degree. In Barbara Partee (ed.), Montague grammar, 261-292. New York: Academic Press.

Heim, Irene. 2001. Degree operators and scope. In Caroline Féry \& Wolfgang Sternefeld (eds.), Audiatur vox sapientiae. A Festschrift for Arnim von Stechow, 214-239.

Heim, Irene. 2004. Remarks on the negation theory of antonymy. Handout.

Heim, Irene. 2007. Little. In Masayuki Gibson \& Jonathan Howell (eds.), Proceedings of SALT XVI, Ithaca: CLC Publications.

Heim, Irene. 2008. Decomposing antonyms? In Atle Grønn (ed.), Proceedings of SuB 12, Oslo: Department of Literature, Area Studies and European Languages, University of Oslo.

Heim, Irene \& Angelika Kratzer. 1998. Semantics in generative grammar. Oxford: Blackwell.

Kennedy, Christopher. 1997. Projecting the adjective: the syntax and semantics of gradability and comparison: University of California, Santa Cruz dissertation.

Kennedy, Christopher. 2001. Polar opposition and the ontology of degrees. Linguistics and Philosophy 24. 33-70.

Kennedy, Christopher. 2007. Vagueness and grammar: the semantics of relative and absolute gradable adjectives. Linguistics and Philosophy 30(1). 1-45.

Klein, Ewan. 1980. A semantics for positive and comparative adjectives. Linguistics and Philosophy 4. 1-45.

Klein, Ewan. 1991. Comparatives. In Dieter Wunderlich \& Arnim von Stechow (eds.), Semantics. an international handbook of contemporary research, 673-691. Berlin, New York: Walter de Gruyter. Dezember 2002.

Krantz, David H., R. Duncan Luce, Patrick Suppes \& Amos Tversky. 1971. Foundations of measurement. New York: Academic Press.

Krasikova, Sveta. 2009. Norm-relatedness in degree constructions. In Arndt Riester \& Torgrim Solstad (eds.), Proceedings of SuB 13, Stuttgart.

Lewis, David. 1970. General semantics. Synthese 22.18-67. 
Rett, Jessica. 2008. Degree modification in natural language: Rutgers University dissertation.

van Rooij, Robert. 2008. Comparatives and quantifiers. In Olivier Bonami \& Patricia Cabredo Hofherr (eds.), Empirical issues in syntax and semantics, vol. 7, 393-414. Paris: Colloque de Syntaxe et Sémantique à Paris.

Rullmann, Hotze. 1995. Maximality in the semantics of wh-constructions: University of Massachusetts, Amherst dissertation.

Russell, Bertrand. 1905. On denoting. Mind 14. 479-493.

Sassoon, Galit. 2007. Vagueness, gradability and typicality. a comprehensive semantic analysis: Tel Aviv University dissertation.

Seuren, Pieter. 1984. The comparative revisited. Journal of Semantics (3). 109-141. von Stechow, Arnim. 1984a. Comparing semantic theories of comparison. Journal of Semantics 3.1-77.

von Stechow, Arnim. 1984b. My reaction to Cresswell's, Hellan's, Hoeksema's and Seuren's comments. Journal of Semantics 3. 183-199.

von Stechow, Arnim. 2006. Times as degrees. MS., University of Tübingen.

von Stechow, Arnim. 2008. Topics in degree semantics: 4 lectures. MS., University of Tübingen.

AUTHOR CONTACT INFORMATION

Svetlana Krasikova

University of Tübingen

Germany

svetakrasikova@me.com 